\title{
Central motor conduction in degenerative ataxic disorders: a magnetic stimulation study
}

\author{
D CLAUS, $\ddagger$ A E HARDING, C W HESS, ${ }^{*}$ K R MILLS, $\dagger$ N M F MURRAY, \\ P K THOMAS
}

From The National Hospital for Nervous Diseases and Institute of Neurology, Queen Square, London, UK

SUMMARY Central motor conduction to small hand muscles was measured using magnetic stimulation of the motor cortex and electrical stimulation of proximal motor roots in 11 patients with Friedreich's ataxia, 10 patients with early onset cerebellar ataxia with retained tendon reflexes (EOCA) and 13 patients with late onset degenerative cerebellar disease (LOCD). Central motor conduction was abnormal in $91 \%$ with Friedreich's ataxia, $70 \%$ with EOCA and $38 \%$ with LOCD. Central motor conduction abnormalities were not specific to individual disorders but were more severe and were related to disease duration in Friedreich's ataxia and EOCA.

The hereditary ataxias are a complex group of disorders which can be classified according to their clinical and genetic features. ${ }^{12}$ There are two main groups, depending on whether the age of onset of symptoms is before or after 20 years. The most frequent early onset disorder in Caucasian populations is Friedreich's ataxia comprising about two thirds of cases of hereditary ataxia. ${ }^{1}$ It is characterised clinically by the onset of symptoms within the first two decades of life, autosomal recessive inheritance, progressive truncal and limb ataxia, dysarthria, absent tendon reflexes, pyramidal signs, distal loss of vibration and joint position sense, foot and spinal deformity, and cardiomyopathy. ${ }^{23}$

Early onset cerebellar ataxia with retained tendon reflexes (EOCA), also of autosomal recessive inheritance, is distinct from Friedreich's ataxia. ${ }^{4}$ The tendon reflexes are normal or increased and optic atrophy, cardiomyopathy, diabetes and severe skeletal deformities are not features of this disease. The clinical prognosis is better and patients remain ambulant on average for 13 years longer than those with Friedreich's ataxia. ${ }^{24}$

Late onset autosomal dominant cerebellar ataxias (ADCA) are often associated with clinical features

Address for reprint requests: N M F Murray, The National Hospital for Nervous Diseases, Queen Square, London WCIN 3BG, UK.

Present addresses: *Neurologische Universitätsklinik, Inselspital, CH3010 Bern, Switzerland. †Radcliffe Infirmary, Oxford OX2 6HE, UK. $\ddagger$ Neurologische Klinik, University of Erlangen, Schwabachanlage 6, D8520 Erlangen, FRG.

Received 10 November 1987 and in revised form 2 February 1988. Accepted 10 February 1988 such as ophthalmoplegia, deafness, optic atrophy, pigmentary retinopathy, dementia, peripheral neuropathy, spasticity, extrapyramidal features and myoclonus. $^{125}$ The underlying pathology is often, but not always, olivopontocerebellar atrophy, although this cannot be established on clinical grounds. Apparently sporadic cases are more common and clinically similar to those of ADCA; these have been referred to as idiopathic late onset cerebellar ataxia (ILOCA). ${ }^{2}$

In Friedreich's ataxia, sensory nerve potentials are usually absent, reflecting loss of large myelinated fibres in peripheral nerves. ${ }^{6-8}$ Somatosensory potentials are delayed and dispersed, indicating disturbance of conduction in the posterior columns. ${ }^{8-10}$ Indirect techniques such as long loop cortical reflexes have shown abnormalities in cases of hereditary ataxia which could indicate either altered central afferent or efferent conduction in Friedreich's ataxia, ${ }^{11}{ }^{12}$ but these cannot be distinguished reliably. A recent study used transcutaneous electrical stimulation of the motor cortex to examine efferent pathways directly ${ }^{13}$; compound muscle action potentials (CMAPs) were reported to be small in severely affected Friedreich's ataxia patients but no data on latencies of responses were provided.

Transcranial magnetic stimulation of the motor cortex represents a major advance in the study of conduction in central motor pathways. ${ }^{14}$ CMAPs evoked by brain stimuli can be recorded from small hand muscles without discomfort, in contrast to transcranial electrical stimulation. When magnetic brain stimulation is used in combination with percutaneous electrical stimulation over the cervical spine, a means 
of exciting the proximal motor roots, ${ }^{15}$ the central motor conduction time (CMCT) can be estimated by subtracting the latency of the latter potential from that of the response to brain stimuli. ${ }^{16}$ CMCT is a measure of conduction in fast-conducting motor pathways, probably from presynaptic structures in the motor cortex, to alpha motoneurons and proximal motor nerve roots. ${ }^{16}$ The technique has been used to demonstrate abnormal conduction in central motor pathways in several neurological disorders, particularly multiple sclerosis where marked CMCT prolongation has been reported. ${ }^{17} 18$ We have used this technique to study conduction in central efferent pathways in 34 patients with degenerative ataxias of various types.

\section{Patients and methods}

Central motor conduction time to the abductor digiti minimi muscle (ADM) was studied in 34 subjects with cerebellar ataxia. The procedures were approved by the Ethics Committee. Patients with a history of epilepsy or neurosurgery or with a cardiac pacemaker were excluded, as were those with ataxia due to known metabolic disorders, alcoholic and paraneoplastic cerebellar atrophy. All patients were examined neurologically at the time of the central motor conduction study. The cases were classified according to Harding ${ }^{2}$ on the basis of genetic and clinical features, and additional tests such as computed tomography, nerve conduction studies and evoked potentials. There were 11 patients with Friedreich's ataxia, 10 with EOCA, 10 with ILOCA and three with ADCA. The last two groups were combined for analysis of CMCT results, this group as a whole being termed late onset cerebellar degenerations (LOCD). Clinical data are shown in table 1 . Disability was assessed as to whether patients (1) were able to walk without help (ambulant); (2) used walking aids, or (3) were wheel-chair bound.

The motor pathways to ADM were studied by per-

Table 1 Degenerative ataxias: clinical features

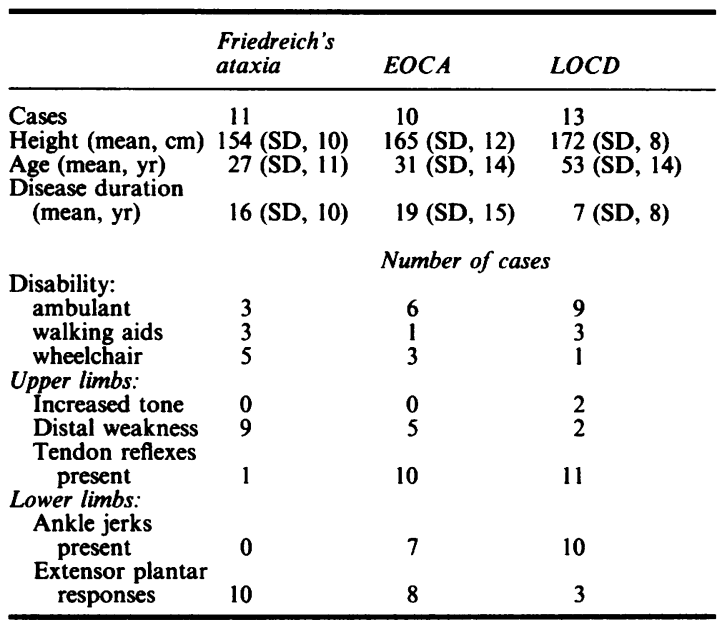

cutaneous electrical stimulation of the ulnar nerve and the motor roots and by magnetic stimulation of the motor cortex. Recordings were made on a conventional electromyograph (Medelec MS8) with silver/silver chloride cup electrodes filled with conducting jelly and attached over the belly and tendon of the ADM (electrode distance $5 \mathrm{~cm}$, amplifier bandpass $20 \mathrm{~Hz}$ to $2 \mathrm{kHz}$ ). The electromyograph was interfaced with a laboratory microcomputer (Research Machines 380Z) for data storage and subsequent analysis. Supramaximal stimuli were applied to the ulnar nerve at the wrist and over the $\mathrm{C} 7 / \mathrm{T} 1$ interspace using an electrical stimulator (Digitimer D180); the proximal motor roots are excited at the intervertebral foramina when the stimulating cathode is placed over the cervical spine and the anode is 6 $\mathrm{cm}$ lateral on the ipsilateral side. ${ }^{15}$

Transcranial stimuli were delivered using a magnetic stimulator, ${ }^{14}$ consisting of a capacitor charged up to a maximum of $4 \mathrm{kV}$ and discharged rapidly into a circular copper coil of inner diameter $9 \mathrm{~cm}$, placed over the subject's vertex. The time course of the magnetic field produced by this coil peaks at approximately $150 \mu \mathrm{s}$ and this induces a stimulating current with a peak at around $80 \mu \mathrm{s} .{ }^{16}$ To measure the cortical response, subjects were asked to maintain slight voluntary abduction of the fifth digit (about 5-10\% maximum force), which is know to facilitate the compound muscle response. The magnetic stimuli were given at increasing intensities to at least $20 \%$ above threshold for facilitated CMAPs. Once reproducible responses were obtained, usually at $60-80 \%$ maximum output of the stimulator, three further stimuli were given. Thus, four responses to motor cortical stimulation were obtained, and measurement was made of the shortest onset latency and largest amplitude of the first negative deflection of the CMAP. ${ }^{16}$ The maximum duration of CMAPs was measured from the beginning of the first negative deflection to the end of the last negative deflection which had at least $10 \%$ of the maximum negative amplitude. In some patients CMAPs were very small and could not be reliably distinguished from the background EMG activity. In these cases the side in question was kept relaxed and the patient made a strong contralateral hand muscle contraction. This method of facilitation causes a shift in latency similar to that when the ipsilateral ADM itself is activated voluntarily. ${ }^{19}$ Responses were regarded as absent when no CMAP was obtained, with ipsilateral or contralateral facilitation, at 95-100\% maximum stimulator output.

Normal data were obtained from 26 male and six female healthy volunteers, aged 21 to 78 years (mean 37, SD12). ${ }^{18}$ Both sides were studied in 17 subjects to assess normal sideto-side variation. CMAPs were easily obtained with stimulation at each site. The mean CMCT on 46 sides of 32 subjects was $6.2 \mathrm{~ms}$ (range $4.5-7 \cdot 7$, SD 0.86 ) and the upper limit of normal was taken as $8.3 \mathrm{~ms}$ (mean $+2.5 \mathrm{SD}$ ). The CMAP duration was $8.6 \mathrm{~ms}$ (SD 1.2). Amplitudes of CMAPs to cortical stimulation ranged from $2 \cdot 1-6 \cdot 7 \mathrm{mV}$; for assessment of normal limits, amplitude was expressed as a percentage of that obtained with stimulation at the wrist and was always at least $18 \%$. The lower limit of normal was set conservatively at $15 \%$. Mean peripheral motor conduction velocity from root and wrist stimulation was $66 \mathrm{~m} / \mathrm{s}$ (range 52-76, SD $5 \cdot 7$, lower limit of normal 52). The upper limit of normal distal motor latency to ADM was $3.3 \mathrm{~ms}$ (range $1 \cdot 6-3 \cdot 3$, mean $2 \cdot 4$, SD $0 \cdot 4$ ). 
Table 2 Degenerative ataxias: physiological results

\begin{tabular}{|c|c|c|c|}
\hline & $\begin{array}{l}\text { Friedreich's } \\
\text { ataxia }\end{array}$ & $E O C A$ & $\angle O C D$ \\
\hline $\begin{array}{l}\text { Cases (n) } \\
\text { Sides (n) }\end{array}$ & $\begin{array}{l}11 \\
21\end{array}$ & $\begin{array}{l}10 \\
19\end{array}$ & $\begin{array}{l}13 \\
24\end{array}$ \\
\hline $\begin{array}{l}\text { DML (mean, ms) } \\
\text { SD; range } \\
\text { abnormal cases/ } \\
\text { sides }\end{array}$ & $\begin{array}{l}2 \cdot 6 \\
0 \cdot 6 ; 1 \cdot 8-4 \cdot 5 \\
1 / 2\end{array}$ & $\begin{array}{l}2 \cdot 9 \\
0 \cdot 9 ; 1 \cdot 8-5 \cdot 0 \\
3 / 5\end{array}$ & $\begin{array}{l}2 \cdot 6 \\
0 \cdot 4 ; 2 \cdot 0-3 \cdot 3 \\
3 / 3\end{array}$ \\
\hline $\begin{array}{l}\text { MNCV (mean, ms) } \\
\text { SD; range } \\
\text { abnormal cases/ } \\
\quad \text { sides }\end{array}$ & $\begin{array}{l}58 \\
5 \cdot 9 ; 49-68 \\
2 / 2\end{array}$ & $\begin{array}{l}61 \\
9 \cdot 8 ; 45-77 \\
3 / 4\end{array}$ & $\begin{array}{l}56 \\
4 \cdot 9 ; 46-67 \\
3 / 4\end{array}$ \\
\hline $\begin{array}{l}\text { CMCT (mean, ms) } \\
\text { SD; range } \\
\text { abnormal cases/ } \\
\quad \text { sides }\end{array}$ & $\begin{array}{l}12 \cdot 7 \\
5 \cdot 2 ; 6 \cdot 1-27 \cdot 1 \\
9 / 16\end{array}$ & $\begin{array}{l}10 \cdot 8 \\
4 \cdot 0 ; 6 \cdot 1-19 \cdot 7 \\
6 / 11\end{array}$ & $\begin{array}{l}7 \cdot 8 \\
3 \cdot 3 ; 4 \cdot 1-17 \cdot 7 \\
5 / 6\end{array}$ \\
\hline $\begin{array}{l}\text { CMAP amplitude } \\
\text { C7/Wrist } \\
(\text { mean, \%) } \\
\text { SD }\end{array}$ & $\begin{array}{l}65 \\
21\end{array}$ & $\begin{array}{l}69 \\
15\end{array}$ & $\begin{array}{l}68 \\
18\end{array}$ \\
\hline $\begin{array}{l}\text { CMAP amplitude } \\
\text { Scalp/Wrist } \\
\text { (mean, \%) } \\
\text { SD; range } \\
\text { abnormal cases/ } \\
\text { sides }\end{array}$ & $\begin{array}{l}14 \\
9 ; 1-32 \\
8 / 12\end{array}$ & $\begin{array}{l}22 \\
19 ; 2-66 \\
5 / 8\end{array}$ & $\begin{array}{l}38 \\
16 ; 8-74 \\
1 / 1\end{array}$ \\
\hline $\begin{array}{l}\text { CMAP duration } \\
\text { C7/Wrist } \\
(\text { mean, \%) } \\
\text { SD }\end{array}$ & $\begin{array}{l}120 \\
15\end{array}$ & $\begin{array}{l}122 \\
16\end{array}$ & $\begin{array}{l}120 \\
18\end{array}$ \\
\hline $\begin{array}{l}\text { CMAP duration } \\
\text { Scalp/Wrist } \\
\text { (mean, \%) } \\
\text { SD; range }\end{array}$ & $\begin{array}{l}306 \\
105 ; 160-533\end{array}$ & $\begin{array}{l}218 \\
99 ; 121-444\end{array}$ & $\begin{array}{l}177 \\
57 ; 109-340\end{array}$ \\
\hline $\begin{array}{l}\text { CMC latency } \\
\text { and/or amplitude } \\
\text { abnormal } \\
\text { cases/sides }\end{array}$ & $10 / 18$ & $7 / 12$ & $5 / 6$ \\
\hline
\end{tabular}

DML $=$ Distal motor latency

MNCV = Motor nerve conduction velocity

CMCT = Central motor conduction time

$\mathrm{CMC}=$ Central motor conduction

CMAP = Compound muscle action potential.

For statistical analysis of findings in the various patient groups, differences between independent samples were assessed using the Mann-Whitney U-Test. Nominal differences were investigated by the $\chi^{2}$-test with Yates' correction. Correlation coefficients were calculated using Spearman's rank correlation test.

\section{Results}

Clinical data on the 34 patients investigated are shown in table 1 . Age and height of patients were generally comparable to the control group, although the Friedreich's ataxia patients were shorter than the others, partly due to scoliosis. The Friedreich's ataxia and EOCA patients were younger and disease duration was longer than in those with LOCD. Friedreich's ataxia patients were slightly but not significantly more disabled than other disease categories when mobility was assessed. Weakness of small hand muscles was present in a much higher proportion of the Friedreich's ataxia cases than the other groups and plantar responses were extensor in all but one with Friedreich's ataxia; that patient had severe paresis of toe extensors. Extensor plantar responses were noted in eight out of 10 EOCA cases but only three with LOCD. Abnormal prolongation of CMCT was found in nine out of 11 FA cases, six out of 10 EOCA cases and five out of 13 with LOCD. When the amplitude of the cortical response was taken into account, 10 Friedreich's ataxia, seven EOCA and five LOCD cases had abnormal central motor conduction (table 2). Typical responses in a patient with Friedreich's ataxia, a patient with EOCA and one with LOCD are illustrated in fig 1 . Responses to cortical stimulation were small and of prolonged latency in the first two patients, but to a greater degree and with greater dispersion in most of the Friedreich's ataxia cases. Figure 2 illustrates CMCT and amplitude findings in all the patients studied. Similar abnormalities of latency and amplitude occurred in patients in all the groups studied, but group comparisons showed significant differences (table 2). Mean CMCT was much longer in Friedreich's ataxia and EOCA than in LOCD (U-test: Friedreich's ataxia/LOCD, p $<0.001$, EOCA/ LOCD, $p=0.01$ ) and correlated with disease duration in Friedreich's ataxia and EOCA (Friedreich's ataxia, $\mathrm{r}=0.55, \mathrm{p}<0.01$; EOCA, $\mathrm{r}=0.42, \mathrm{p}<$ $0.05)$. CMCT was also significantly correlated with disability in Friedreich's ataxia and EOCA (Friedreich's ataxia, $\mathrm{r}=0.58, \mathrm{p}<0.005$; EOCA, $r=0.65, p<0.005)$. There were three Friedreich's ataxia cases who were ambulant at the time of the study. CMCT was abnormal in 2, with disease durations of 1 and 6 years but was normal in one case despite an 11 year history.

Abnormal CMCT occurred less frequently in EOCA than in Friedreich's ataxia, and CMCT was entirely normal in three subjects with disease durations of 27, 16 and 8 years. CMCT was normal in eight out of 13 cases with LOCD including subjects symptomatic for as long as 30 years. LOCD patients with normal CMCT were not distinct clinically from those with abnormal central conduction, and were certainly not less severely affected.

The mean interside difference of CMCT was higher in Friedreich's ataxia ( $4.7 \mathrm{~ms}$, SD 4.2$)$ compared with EOCA (1.4, SD 1.9) and LOCD (1.9, SD 1.6). However, eight out of nine abnormal Friedreich's ataxia cases in which both hands were investigated had bilaterally prolonged CMCT. CMCT was bilaterally prolonged in five out of six abnormal EOCA cases and in only one out of five abnormal LOCD cases when both 
FA

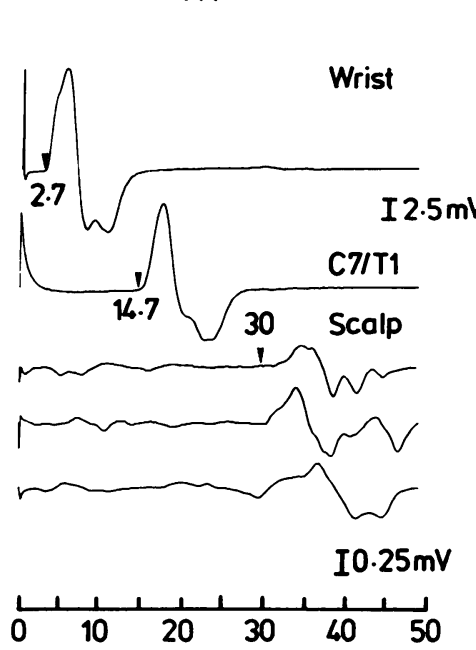

EOCA

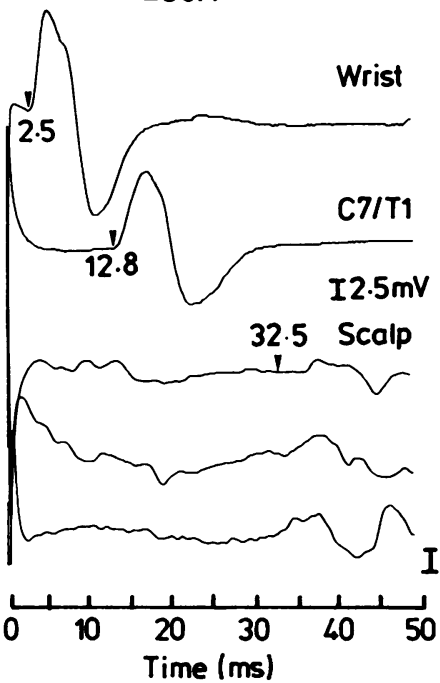

ILOCA

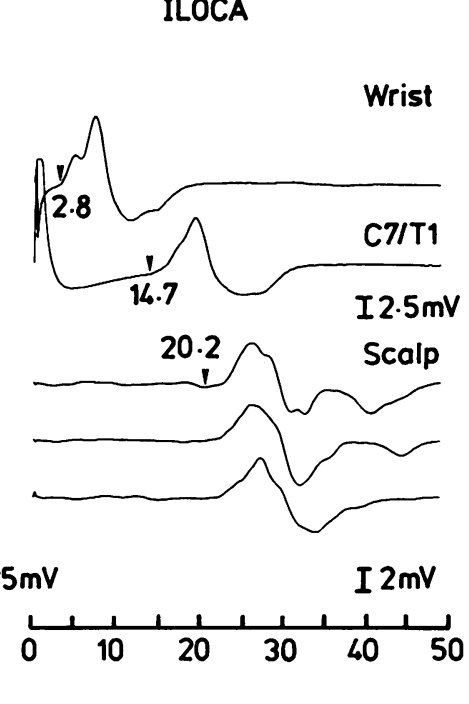

Fig 1 CMAPs recorded from right ADM with, from above, electrical stimulation at wrist, and C7/T1 interspace, and magnetic stimulation over the scalp vertex (three responses). Left: Friedreich's ataxia, CMCT 15.3 ms. Middle: patient with EOCA, CMCT $19.7 \mathrm{~ms}$. Right: patient with ILOCA, CMCT $5.5 \mathrm{~ms}$. The figure illustrates the variability of responses to brain stimulation.

hands were investigated. The amplitude of responses to brain stimulation was larger in LOCD than in Friedreich's ataxia and EOCA (U-test: Friedreich's ataxia/LOCD, p < 0.001, EOCA/LOCD, p < 0.01), whereas duration of cortical responses (not regarded as a criterion of abnormality) was significantly longer in Friedreich's ataxia than in the other disorders (U-test: Friedreich's ataxia/EOCA, p $<0.01$,

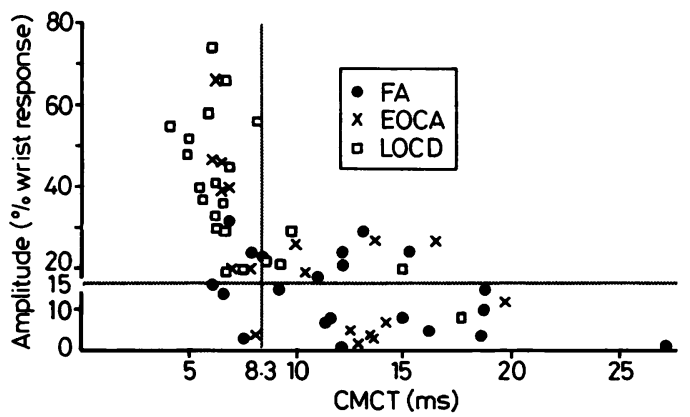

Fig 2 Responses from 64 sides of 34 patients with cerebellar ataxia. CMCT is plotted against amplitude of the cortical response, expressed as percentage of wrist response. Vertical and horizontal lines indicate limits of normal CMCT and amplitude respectively. Open symbols represent measurement of patients with LOCD, crosses those with EOCA, filled circles those with Friedreich's ataxia. Long CMCT and low amplitude values are seen especially in Friedreich's ataxia and EOCA.
Friedreich's ataxia/LOCD, $p<0.001)$, as shown in fig 3.

The amplitude and duration of responses evoked by root stimulation were similar in all three groups and there was no significant difference in distal latency or MCV along the ulnar nerve between the groups; virtually all cases were normal.

No adverse effects of the procedure were reported or noted in any of the patients or control group.

\section{Discussion}

The clinical and pathological features of Friedreich's

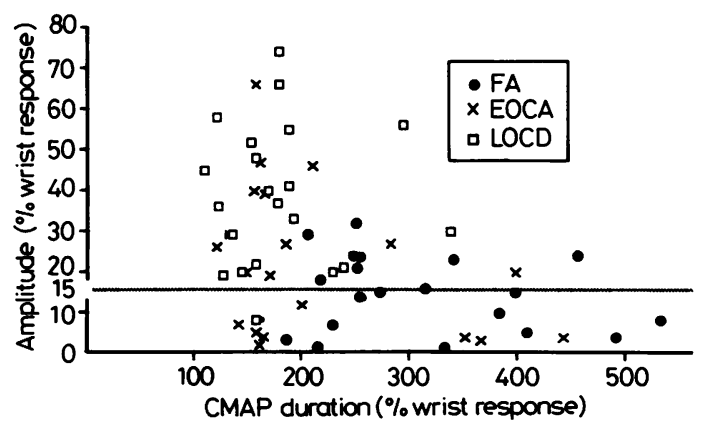

Fig 3 The duration of the CMAP evoked by brain stimulation is plotted against amplitude: both are expressed as percentage of wrist response. Same symbols as in fig 2. 
ataxia and the attendant electrophysiological findings are in general well described, although modern morphological information on the corticospinal tracts is surprisingly limited. It is known that there is shrinkage and reduction in number of Betz cells in the motor cortex with diffuse sclerosis of the internal capsules and pyramidal tract degeneration in the spinal cord $^{20-23}$ but these structures have until now been relatively inaccessible to the physiologist. Such studies as there have been have not wholly separated the central efferent component from, on the one hand, the afferent pathways and, on the other, the peripheral motor system, since there is some loss of anterior horn cells and motor fibres as well as severe degeneration of the posterior columns and spinocerebellar tracts. ${ }^{11} 12$

Little is known of the pathology in EOCA although one report suggests that the cerebellum and brainstem are particularly affected. ${ }^{24}$ Pyramidal tract involvement would be expected from the clinical features. In many patients with LOCD, olivopontocerebellar or cerebello-olivary atrophy is seen at necropsy, and these may be accompanied by corticospinal tract degeneration. ${ }^{20}$

Central motor conduction, as measured in this study, was abnormal in almost all the Friedreich's ataxia cases examined; this is consistent with our understanding of the disorder and indicates the sensitivity of the technique in the study of central motor pathways. Characteristically CMAPs on magnetic brain stimulation were attenuated and bilaterally delayed (fig 2). A normal central motor conduction study, although not ruling out the diagnosis of Friedreich's ataxia, must lead to a reassessment of the case. A high incidence of central motor conduction abnormality was also found in EOCA, but less than in Friedreich's ataxia. This suggests that the retention of tendon reflexes which particularly differentiates this condition from Friedreich's ataxia is due mainly to preservation of the afferent section of the reflex arc, rather than more severe corticospinal tract disease. Some EOCA cases, even with long histories, had normal central motor conduction and this raises the possibility that EOCA is a heterogeneous disorder rather than a single entity. Marked variability in central motor conduction in LOCD would also suggest heterogeneity, as expected from the clinical and pathological findings in this condition. CMAP amplitudes were higher than in Friedreich's ataxia (fig 2) and CMCT was prolonged often only unilaterally.

Studies of central motor conduction by magnetic stimulation in other neurological disorders have demonstrated that the abnormalities encountered in this study are not specific to any single pathological process. Prolongation of CMCT may be due to slowed conduction in demyelinated fibres but a similar delay might be caused by conduction in smaller fibres of the same tract due to selective loss of large fibres, by utilisation of another, oligosynaptic pathway or by reduction in the size or synchrony of the efferent volley impinging on the anterior horn cell. ${ }^{25}$ Thus axon loss alone can cause CMCT prolongation and values as high as $\mathbf{2 0} \mathrm{ms}$ have been recorded in motor neuron disease $^{18}$ and cerebrovascular disease (unpublished observation) as well as in multiple sclerosis. ${ }^{1718}$ CMCT as measured here includes a small peripheral component of around $1.5 \mathrm{~ms}$ due to synaptic delay and conduction in the $\mathrm{C} 8$ and $\mathrm{T} 1$ motor roots proximal to the intervertebral foramina; none of the cases studied had slowing of conduction in the peripheral nerves which was significant in itself to prolong CMCT. Furthermore, it has been shown previously that CMCT can be successfully studied by both electrical and magnetic brain stimulation in the presence of severe peripheral neuropathy. ${ }^{26}{ }^{27}$ One striking feature of the present study was the much greater duration and apparent temporal dispersion of responses to cortical stimulation in Friedreich's ataxia compared with the other disorders. No similar phenomenon was seen on wrist or root stimulation. The pathophysiological significance of this observation is uncertain; single stimuli to the motor cortex cause a train of descending impulses which may result in repetitive firing of anterior horn cells in normal subjects. ${ }^{16}$ Whether the potential duration differences noted here represent qualitatively distinct pathological processes, or are simply a matter of degree, has yet to be established.

This work was supported by the Deutsche For schungsgemeinschaft, the Multiple Sclerosis Society, and the Friedreich's Ataxia Group.

\section{References}

1 Harding AE. Classification of the hereditary ataxias and paraplegias. Lancet 1983;i:1151-55.

2 Harding AE. The Hereditary Ataxias and Related Disorders. London: Churchill Livingstone, 1984.

3 Geoffroy G, Barbeau A, Breton A, et al. Clinical description and roentgenologic evaluation of patients with Friedreich's ataxia. Can J Neurol Sci 1976;3:279-86.

4 Harding AE. Early onset cerebellar ataxia with retained reflexes. A clinical and genetic study of a disorder distinct from Friedreich's ataxia. J Neurol Neurosurg Psychiatry 1981;44: 503-8.

5 Schut JW. Hereditary ataxia: clinical study through six generations. Arch Neurol Psychiatr 1950;63:535-68.

6 McLeod JG. An electrophysiological and pathological study of peripheral nerves in Friedreich's ataxia. J Neurol Sci 1971;12: 333-49.

7 Ouvrier RA, McLeod JG, Conchin TE. Friedreich's ataxia: early detection and progression of peripheral nerve abnormalities. J Neurol Sci 1982;55:137-45.

8 Sauer M. Somatosensible Leitungsmessungen bei neurologischen 
Systemerkrankungen. Neurale Muskelatrophien und spinocerebelläre Ataxien. Arch Psychiatr Nervenkr 1980;228: $223-42$.

9 Caruso G, Santoro L, Perretti A, et al. Friedreich's ataxia: electrophysiologic and histologic findings in patients and relatives. Muscle Nerve 1987;10:503-15.

10 Jones SJ, Baraitser M, Halliday AM. Peripheral and central somatosensory nerve conduction in Friedreich's ataxia. $J$ Neurol Neurosurg Psychiatry 1980;43:495-503.

11 Claus D, Schöcklmann HO, Dietrich HJ. Long latency muscle responses in cerebellar diseases. Eur Arch Psychiatr Neurol Sci 1986;235:355-60.

12 Friedemann HH, Noth J, Diener HC, Bacher M. Long latency EMG responses in hand and leg muscles: cerebellar disorders. J Neurol Neurosurg Psychiatry 1987;50:71-77.

13 Perretti A, Santoro L, Pelosi L, Lanzillo B, Filla A, Caruso G. Central motor conduction study of Friedreich's ataxia (FA). Electroencephalogr Clin Neurophysiol 1987;66:S80.

14 Barker AT, Jalinous R, Freeston IL. Non-invasive magnetic stimulation of the human motor cortex. Lancet 1985;i:1106-7.

15 Mills KR, Murray NMF. Electrical stimulation over the human vertebral column: which neural elements are excited? Electroencephalogr Clin Neurophysiol 1986;63:582-9.

16 Hess CW, Mills KR, Murray NMF. Responses in small hand muscles from magnetic stimulation of the human brain. $J$ Physiol (London) 1987;388:397-419.

17 Hess CW, Mills KR, Murray NMF. Measurement of central motor conduction in multiple sclerosis by magnetic brain stimulation. Lancet 1986;ii:355-58.
18 Hess CW, Mills KR, Murray NMF, Schriefer TN. Magnetic brain stimulation: central motor conduction studies in multiple sclerosis. Ann Neurol 1987;22:744-52.

19 Hess CW, Mills KR, Murray NMF. Magnetic stimulation of the human brain: facilitation of motor responses by voluntary contraction of ipsilateral and contralateral muscles with additional observations on an amputee. Neurosci Lett 1986;71: 235-40.

20 Greenfield JG. The Spino-cerebellar Degenerations. Oxford: Blackwell Scientific Publications, 1954.

21 Oppenheimer DR. Brain lesions in Friedreich's ataxia. Can J Neurol Sci 1979;6:173-76.

22 Mott FW. Case of Friedreich's disease, with autopsy and systematic microscopical examination of the nervous system. Arch Neurol Path Lab London County Asylums 1907;3:180-200.

23 Rennie GE. A case of Friedreich's ataxia with necropsy. Br Med $J$ 1899;2:129-31.

24 Fickler A. Klinische und pathologisch-anatomische Beiträge zu den Erkrankungen des Kleinhirns. Dtsch Zeitschr Nervenheilk 1911;41:306-75.

25 Felix D, Wiesendanger M. Pyramidal and non-pyramidal motor cortical effects on distal forelimb muscles of monkeys. Exp Brain Res 1971;12:81-91.

26 Hess CW, Mills KR, Murray NMF. Central motor conduction in hereditary motor and sensory neuropathy (HMSN). Electroencephalogr Clin Neurophysiol 1987;66:S46.

27 Thomas PK, Walker RWH, Rudge P, et al. Chronic demyelinating peripheral neuropathy associated with multifocal central nervous system demyelination. Brain 1987;110:53-76. 